\title{
Epithelioid sarcoma
}

INSERM

\section{Source}

INSERM. (1999). Orphanet: an online rare disease and orphan drug data base. Epithelioid sarcoma. ORPHA:293202

Epithelioid sarcoma is a rare, soft tissue tumor characterized by high incidence of local recurrence, regional lymph node involvement and distant metastases. It commonly affects the soft tissue under the skin of a finger, hand, forearm, lower leg or foot, less often other areas of the body. 